\title{
Epidemiologic characteristics of oral cancer: single-center analysis of 4097 patients from the Sun Yat-sen University Cancer Center
}

\author{
Ji Zhang ${ }^{1,2 \dagger}$, Fan Gao 1,2†, An-Kui Yang 1,2, Wen-Kuan Chen 1,2, Shu-Wei Chen 1,2, Huan Li ${ }^{1,3}$, Xing Zhang ${ }^{1,2}$, \\ Zhong-Yuan Yang ${ }^{1,2}$, Xin-Lin Chen ${ }^{4^{*}}$ and Ming Song ${ }^{1,2^{*}}$
}

\begin{abstract}
Background: Oral cancer is a common type of head and neck cancers. Knowing its epidemiologic characteristics is crucial to preventing, diagnosing, and treating this cancer. This study aimed to explore the epidemiologic characteristics of oral cancer in South China.

Methods: We retrospectively analyzed data from 4097 oral cancer patients treated at the Sun Yat-sen University Cancer Center between 1960 and 2013. We compared the age of onset, sex ratio, pathologic type, and primary tumor location among three subcultural areas (Guangfu, Hakka, and Chaoshan) and between an economically developed region and a less-developed one in Guangdong.

Results: Overall, oral cancer had a male-to-female ratio of approximately 2:1, and this ratio decreased over time. Oral cancer occurred mostly in patients of 45-64 years old (54.5\%), and the percentage of older patients gradually increased over time. The most common tumor location was the tongue. Squamous cell carcinoma was the predominant pathologic type. The percentage of blood type $O$ in oral cancer patients was lower than that in the healthy population. The male-to-female ratio in the Chaoshan area was higher than that in the Guangfu and Hakka areas, whereas the age of disease onset in Guangfu was higher than that in Hakka and Chaoshan. The male-to-female ratio was lower and the age of disease onset was higher in the economically developed region than in the less-developed region.

Conclusion: The incidence of oral cancer in South China presents typical characteristics to which doctors should pay attention when diagnosing and treating oral cancer patients.
\end{abstract}

Keywords: Oral cancer, Epidemiology, Guangdong

\section{Background}

More than two million deaths of cancer per year [1] make it a major public issue in China. Worldwide, the 263,900 cases of oral cancer per year make it the 10th

\footnotetext{
*Correspondence: chenxlsums@126.com; songming@sysucc.org.cn

${ }^{\dagger} \mathrm{ji}$ Zhang and Fan Gao have contributed equally to this work

${ }^{1}$ State Key Laboratory of Oncology in South China, Collaborative Innovation Center of Cancer Medicine, Sun Yat-sen University Cancer Center, 651 Dongfeng Road East, 510060 Guangzhou, Guangdong, P. R. China

${ }^{4}$ Department of Preventive Medicine and Biostatistics, School of Basic Medical Science, Guangzhou Higher Education Mega Center, Guangzhou University of Chinese Medicine, 232 Outer Ring East Road, 510006 Guangzhou, Panyu District, Guangdong, P. R. China

Full list of author information is available at the end of the article
}

most common cancer in men [2]. The incidence of oral cancer is widely believed to be associated with the use of tobacco, alcohol, betel quid (a vine with mild stimulant properties), and areca nut (a palm nut with mild stimulant properties often chewed with betel quid) [3]. People of lower socioeconomic class may also be more prone to oral cancer than those of higher class [4], perhaps because of poor oral hygiene and nutrition. Some researchers believe that the incidence is also associated with air pollution [5].

The Sun Yat-sen University Cancer Center is the largest cancer hospital in Guangdong Province and in South China and treats more cancer patients than most hospitals in this region. Therefore, patients treated in this 
center largely present with typical characteristics of diseases in this region, including oral cancer, which is a major disease diagnosed and treated here. We retrospectively analyzed data from patients with oral cancer treated at the cancer center to determine the disease characteristics prevalent in South China, with the aim of providing a sound knowledge base for its prevention, diagnosis, and treatment.

\section{Methods}

\section{Patient collection}

Data from all patients with oral cancer treated at the Sun Yat-sen University Cancer Center between 1960 and 2013 were collected. All the patients were diagnosed by pathologic analysis.

\section{Data collection}

In addition to standard demographic data, we collected data on the date of hospital admission, location of the primary tumor, blood type, native place, long-term residence, and so on.

Patients were classified into five groups by period of admission (1960-1973, 1974-1983, 1984-1993, 19942003, and 2004-2013) and seven age groups (0-24, $25-34,35-44,45-54,55-64,65-74$, and $\geq 75$ years).

The location of the primary tumor in each patient was identified as being in one of six parts of the mouth: the body of the tongue (the front two-thirds of the tongue, not including the root), the floor of the mouth, the buccal mucosa, the alveolus, the retromolar area, and the hard palate (not including the soft palate).

Guangdong Province was divided into three subcultural, geographic areas according to residents' dialects, diets, and living habits: Guangfu (also known as Cantonese, including Guangzhou, Shenzhen, Zhuhai, Foshan, Zhanjiang, Zhaoqing, Jiangmen, Maoming, Yangjiang, Qingyuan, Dongguan, Zhongshan, and Yunfu), Hakka (Meizhou, Huizhou, Heyuan, and Shaoguan), and Chaoshan (Chaozhou, Shantou, Jieyang, and Shanwei). Patients' native places were classified into one of these three geographic areas.

Guangdong was further divided into two regions: the Pearl River Delta region (Guangzhou, Shenzhen, Zhuhai, Foshan, Zhaoqing, Jiangmen, Huizhou, Dongguan, and Zhongshan) and the non-Pearl River Delta region. The Pearl River Delta region is markedly more economically developed [6]. Patients' long-term residences were classified in these two geographic regions.

\section{Statistical analysis}

All data were sorted and analyzed with SPSS 21.0 (SPSS Inc., Chicago, IL, USA). Alpha was set at 0.05, and all tests were two-tailed. Frequencies and proportions were calculated for the demographic data. The Chi square test was used to analyze the associations of oral cancer with sex and blood type. The Analysis of Variance (ANOVA) was used when analyzing the age distribution. The Bonferroni correction was applied for multiple comparisons.

\section{Results}

Data from 4097 patients, 2729 males and 1368 females, were analyzed (Table 1).

\section{Age distribution}

The median age of disease onset of the patients was 53 years (range, 3-97 years). The age of onset was concentrated between the ages of 45 and 64 years (Table 2). In addition, over the study period of approximately 50 years, the percentage of older patients significantly increased $(F=17.29, P<0.001)$.

\section{Tumor location}

Most tumors were on the tongue (64.3\%), followed by the gingiva, hard palate, buccal mucosa, floor of the mouth, lips, and retromolar area (Table 3).

\section{Pathologic type}

Squamous cell carcinoma was the most common type of oral cancer (88.9\%; Table 3). Of the 3642 cases of squamous cell carcinoma, 2126 were highly differentiated, 928 were moderately differentiated, 289 were poorly differentiated, and 299 were unknown.

\section{Blood type}

The blood type of 265 patients was not identified. The distribution of blood types of the remaining patients is presented in Table 3.

\section{Distribution of native places}

Most patients were Cantonese (3630 patients). The distributions of Cantonese patients by their native places were Guangfu (2470), Hakka (488), Chaoshan (481), and unknown (191).

The male-to-female ratio differed significantly in the three subcultural areas $\left(\chi^{2}=6.36, P<0.05\right)$. Pairwise comparisons indicated that the ratio in the Chaoshan area was significantly higher than those in the Hakka and Guangfu areas (Table 1).

The age of disease onset also differed significantly among the three subcultural areas $(F=9.96, P<0.001)$. Pairwise comparisons indicated that the age of disease onset in Guangfu was significantly higher than those in Hakka and Chaoshan (Table 2). 
Table 1 Residential and hospital admission characteristics of 4097 oral cancer patients in South China by sex

\begin{tabular}{lrrrrr}
\hline Variate & Total & Male & Female & M:F ratio & $P$ \\
\hline Period of hospital admission & 4097 & 2729 & 1368 & 1.99 & $<0.05$ \\
1960-1973 & 432 & 293 & 139 & 2.11 & \\
$1974-1983$ & 500 & 344 & 156 & 2.21 & \\
$1984-1993$ & 803 & 549 & 254 & 2.16 & \\
$1994-2003$ & 959 & 635 & 324 & 1.96 & \\
2004-2013 & 1403 & 908 & 495 & 1.83 & \\
Subcultural area & 3630 & 2418 & 1212 & 2.00 & $<0.05$ \\
Guangfu (Cantonese) & 2470 & 1602 & 868 & 1.85 & \\
Hakka & 488 & 315 & 173 & 1.82 & \\
Chaoshan & 481 & 340 & 141 & 2.41 & \\
Unknown & 191 & 161 & 30 & 5.37 & \\
Economic region ${ }^{\text {b }}$ & 3661 & 2427 & 1234 & 1.97 & $<0.05$ \\
Pearl river delta region & 2479 & 1617 & 862 & 1.88 & \\
$\quad$ Non-pearl river delta & 1072 & 736 & 336 & 2.19 & \\
$\quad$ region & & & & & \\
Unknown & 110 & 74 & 36 & 2.06 & \\
\hline
\end{tabular}

${ }^{a}$ A total of 467 non-Cantonese patients were excluded from this analysis

${ }^{b}$ A total of 436 patients who live in other provinces were excluded from this analysis

\section{Economic conditions}

A total of 436 patients who live in other provinces were excluded from this analysis. Of the 3661 residents in Guangdong, 2479 lived in the Pearl River Delta region, 1072 lived in the non-Pearl River Delta region, and 110 were unknown. The male-to-female ratio differed significantly between these two regions $\left(\chi^{2}=3.94, P<0.05\right)$, with a higher ratio in the Pearl River Delta region (Table 1). Age at disease onset differed significantly between the Pearl River Delta and non-Pearl River Delta regions $(F=31.51, P<0.001)$, with an older age at disease onset in the Pearl River Delta region (Table 2).

\section{Discussion}

According to our study, the incidence of oral cancer differs by sex, age, blood type, life style, and economic condition.

The incidence of oral cancer in males was significantly higher than that in females. The male-to-female ratio is 10.5 in Taiwan, China [7] and 1.42 in the United States [8]. The male-to-female ratio in the present study was approximately two. This disparity may result from sex differences in exposure to risk factors for oral cancer [8, 9]. For example, men generally consume more alcohol and cigarettes than women.

In the present study, the male-to-female ratio showed a slightly downward trend, and the percentage of female oral cancer patients gradually increased from $32.2 \%$ in 1960 s to $35.3 \%$ now. Other investigators have reported similar findings. For example, the worldwide epidemiologic study of oral cancer by Warnakulasuriya et al. [9] found that the male-to-female ratio of oral cancer had decreased in recent decades, which might be associated with changes in the degree of exposure to risk factors.

Table 2 Residential and hospital admission characteristics of 4097 oral cancer patients in South China by age at admission

\begin{tabular}{|c|c|c|c|c|c|c|c|c|c|}
\hline \multirow[t]{2}{*}{ Variate } & \multirow[t]{2}{*}{ Total } & \multicolumn{7}{|c|}{ Age (years) } & \multirow[t]{2}{*}{$P$} \\
\hline & & $0-24$ & $25-34$ & $35-44$ & $45-54$ & $55-64$ & $65-74$ & $75-$ & \\
\hline Period of hospital admission & 4097 & 96 & 287 & 711 & 1056 & 1178 & 622 & 147 & $<0.001$ \\
\hline $1960-1973$ & 432 & 17 & 36 & 110 & 103 & 114 & 48 & 4 & \\
\hline 1974-1983 & 500 & 10 & 44 & 83 & 171 & 131 & 54 & 7 & \\
\hline 1984-1993 & 803 & 22 & 55 & 145 & 197 & 250 & 119 & 15 & \\
\hline 1994-2003 & 959 & 16 & 68 & 157 & 236 & 270 & 162 & 50 & \\
\hline $2004-2013$ & 1403 & 31 & 84 & 216 & 349 & 413 & 239 & 71 & \\
\hline Subcultural area ${ }^{a}$ & 3630 & 86 & 239 & 623 & 927 & 1049 & 569 & 137 & $<0.001$ \\
\hline Guangfu (Cantonese) & 2470 & 46 & 152 & 402 & 612 & 740 & 421 & 97 & \\
\hline Hakka & 488 & 16 & 33 & 95 & 142 & 129 & 58 & 15 & \\
\hline Chaoshan & 481 & 12 & 42 & 95 & 134 & 133 & 50 & 15 & \\
\hline Unknown & 191 & 12 & 12 & 31 & 39 & 47 & 40 & 10 & \\
\hline Economic region ${ }^{b}$ & 3661 & 86 & 251 & 630 & 929 & 1054 & 575 & 136 & $<0.001$ \\
\hline Pearl river delta region & 2479 & 41 & 145 & 394 & 627 & 738 & 433 & 101 & \\
\hline Non-pearl river delta region & 1072 & 33 & 92 & 213 & 279 & 295 & 130 & 30 & \\
\hline Unknown & 110 & 12 & 14 & 23 & 23 & 21 & 12 & 5 & \\
\hline
\end{tabular}

a total of 467 non-Cantonese patients were excluded from this analysis

b A total of 436 patients who live in other provinces were excluded from this analysis 
Table 3 Disease characteristics of 4097 oral cancer patients in South China

\begin{tabular}{|c|c|c|}
\hline Variate & Number of cases & Percentage (\%) \\
\hline Tumor location & 4097 & \\
\hline Body of tongue & 2230 & 54.4 \\
\hline Floor of mouth & 305 & 7.4 \\
\hline Buccal mucosa & 367 & 9.0 \\
\hline Gingiva & 534 & 13.0 \\
\hline Retromolar area & 18 & 0.4 \\
\hline Hard palate & 381 & 9.3 \\
\hline Lips & 187 & 4.6 \\
\hline Unknown & 75 & 1.8 \\
\hline Pathologic type & 4097 & \\
\hline Squamous cell carcinoma & 3642 & 88.9 \\
\hline Adenoid cystic carcinoma & 119 & 2.9 \\
\hline Mucoepidermoid carcinoma & 77 & 1.9 \\
\hline Malignant melanoma & 48 & 1.2 \\
\hline Adenocarcinoma & 32 & 0.8 \\
\hline Basaloid carcinoma & 28 & 0.7 \\
\hline Malignant mixed tumor & 25 & 0.6 \\
\hline Sarcoma & 22 & 0.5 \\
\hline Myoepithelial carcinoma & 4 & 0.1 \\
\hline Others & 100 & 2.4 \\
\hline Blood type & 4097 & \\
\hline A & 1021 & 24.9 \\
\hline B & 1039 & 25.4 \\
\hline$A B$ & 253 & 6.2 \\
\hline $\mathrm{O}$ & 1519 & 37.1 \\
\hline Unknown & 265 & 6.5 \\
\hline
\end{tabular}

In our study, half the patients were between 45 and 64 years old. This result is consistent with most other reports. For example, Wen et al. [10] reported that the highest prevalence was between the ages of 41 and 60 years.

In the present study, over approximately 50 years, the percentage of younger patients with oral cancer gradually decreased, whereas the percentage of older patients gradually increased. This change may be explained by the fact that, in recent decades, the Chinese economy has been rapidly expanded and living conditions have been rapidly improved. Additionally, due to the implementation of family planning policies, the size of the aging population has increased, with a consequent increase in the proportion of older people in the population. Increased life span, resulting from the improved living conditions, has further increased this proportion. Therefore, the increase in the proportion of older patients may not reflect an actual increase in the incidence in older people.

The most common tumor sites of oral cancer in the United States are the tongue, alveolus, and lips [11]. Data from Southeast China showed that the three most common locations were the tongue, floor of the mouth, and gingiva in males and the tongue, buccal mucosa, and gingiva in females [12]. In the present study, we found that two-thirds of tumors were on the tongue, followed by the gingiva, hard palate, buccal mucosa, floor of the mouth, lips, and retromolar area.

As in most other reports, our study also found that the cancer type with the highest incidence was squamous cell carcinoma, which accounted for nearly $90 \%$ of cancers. In West China, approximately two-thirds of oral and maxillofacial malignant tumors were squamous cell carcinomas [10]. Other common types in our study were malignant lymphoma, mucoepidermoid carcinoma, adenoid cystic carcinoma, and adenoma. However, we found fewer lymphomas than that reported in West China, perhaps because we excluded cases of cancer in the oropharynx, which includes locations such as the tonsils, soft palate, and root of the tongue.

Many reports have shown that the $\mathrm{ABO}$ blood type system is associated with the development of cancers. Type A has been associated with gastric [13-15], pancreatic [16-19], ovarian [16, 20], esophageal [21], salivary gland [21], and breast cancers [16], whereas type B has been associated with esophageal $[22,23]$ and laryngeal cancers [21]. Some reports showed that people with blood type O have lower risks for lung [24], endometrial [25], pancreatic [26], renal cell [27], and ovarian cancers [28], and colorectal adenocarcinoma [29]. However, we found no studies that assessed the association between blood type and oral cancer. We combined the data for types $\mathrm{A}, \mathrm{B}$, and $\mathrm{AB}$ (type other) and compared the proportions of blood types for our patients with control data from a representative sample of the Guangdong population published by Chen et al. [30]. Of our patients, 1519 had type $\mathrm{O}$ and 2313 had type other, whereas in the control group, 10,702 had type $O$ and 14,210 had type other. The proportion of oral cancer patients with type O blood was significantly lower than that of controls $\left(\chi^{2}=14.97\right.$, $P<0.001$ ).

In this study, almost $90 \%$ of our patients were Cantonese. There are three major subcultural areas in Guangdong province: Guangfu, Hakka, and Chaoshan. The dialects, diets, and living habits in these three areas differ markedly. The male-to-female ratio of oral cancer patients in the Chaoshan area was significantly higher than that in the Guangfu and Hakka areas, the possible reasons for which are as follows. Smoking and drinking are more prevalent in the Chaoshan area, with men more often addicted to drinking and smoking than women. It is well known that drinking [31,32] and smoking [31, 33-35] promote the development and progression of oral cancer. In addition, in most families in the Chaoshan 
area, men are absolutely dominant; therefore, if women experience symptoms, they might remain silent, or their complaint may not receive enough attention from family members, leading to lower diagnosis and treatment rates in large hospitals.

The age of onset in patients from the Guangfu area was older than that of the other two areas. It is possible that the lifestyle habits of people in Hakka and Chaoshan more likely lead to early exposure to carcinogenic factors. For example, Chaoshan people like to drink very hot Kungfu tea (often approximately $75^{\circ} \mathrm{C}$ or $167^{\circ} \mathrm{F}$ ). Hakka cuisine also stresses that food should be eaten when it is hot. Eating very hot food or tea has been reported to increase the risk of gastrointestinal tumors through mucosal damage, inflammatory factors, and heat shock protein activity $[36,37]$. The high incidence of esophageal cancer and laryngeal cancer in this area might be associated with this habit. Hakka cuisine uses more salt and oil. Excessive salt or oil intake is associated with the development of tumors [38]. Chaoshan people like pickled food, fish sauce, and barbecued food, which are considered to have cancer-promoting effects [38, 39]. The prevalence of smoking and drinking in the Chaoshan area could also significantly increase the incidence of oral cancer.

The Pearl River Delta region is markedly more economically developed than the rest of Guangdong province. The male-to-female ratio of oral cancer patients in the non-Pearl River Delta region was significantly higher than that in the Pearl River Delta region, possibly because bad health habits, such as drinking and smoking, were more common in people, mainly males, in the economically underdeveloped regions.

The mean age of disease onset in the Pearl River Delta region was higher than that in the non-Pearl River Delta region. It is possible that people in the economically underdeveloped regions had a higher chance of encountering carcinogenic factors at an early age than those in the developed regions. For example, a poor working environment [40], poor nutritional status and developmental retardation [36, 41], a low education level [38], low awareness of dental care and poor oral hygiene [42], common poor health habits (such as excessive drinking and smoking), few physical examinations for cancer prevention, and low levels of medical care [40] would affect the age distribution of oral cancer patients.

This study design is a retrospective single center analysis, so an unavoidable problem is missing data. We drew conclusions about the epidemiologic features of oral cancer in different areas from some indirect evidence. Prospective controlled studies need be carried out to support our conclusions.

\section{Conclusions}

We infer from our data that during the process of screening for oral cancer, clinicians should pay attention to middleaged and older people, men, and individuals with non-O blood type. Physicians should pay attention to every corner of the oral cavity and focus on examining sites of predilection. To help prevent the development of oral cancer, targeted information should be disseminated to encourage residents to change poor lifestyle habits. We should also appeal to the government to increase investment in medical care in economically underdeveloped regions.

\section{Authors' contributions}

JZ participated in the design of the study and drafted the manuscript. FG carried out the data interpretation and took part in the study design. AY and WC participated in conceiving the study. SC and $\mathrm{HL}$ carried out the data collection and participated in the design of the study. XZ and ZY participated in the data collection. XC performed the statistical analysis and participated in the design of the study. MS conceived and designed the study, and directed the writing of the manuscript. All authors read and approved the final manuscript.

\section{Author details}

${ }^{1}$ State Key Laboratory of Oncology in South China, Collaborative Innovation Center of Cancer Medicine, Sun Yat-sen University Cancer Center, 651 Dongfeng Road East, 510060 Guangzhou, Guangdong, P. R. China. ${ }^{2}$ Department of Head and Neck Surgery, Sun Yat-sen University Cancer Center, 510060 Guangzhou, Guangdong, P. R. China. ${ }^{3}$ Department of Intensive Care, Sun Yat-sen University Cancer Center, 510060 Guangzhou, Guangdong, P. R. China. ${ }^{4}$ Department of Preventive Medicine and Biostatistics, School of Basic Medical Science, Guangzhou Higher Education Mega Center, Guangzhou University of Chinese Medicine, 232 Outer Ring East Road, 510006 Guangzhou, Panyu District, Guangdong, P. R. China.

\section{Acknowledgements}

This study was supported by grants from the National Natural Science Foundation of China (No. 81172568).

\section{Competing interests}

The authors declare that they have no competing interests.

Received: 9 May 2015 Accepted: 30 November 2015

Published online: 03 March 2016

\section{References}

1. Chen W, Zheng R, Zeng H, Zhang S. The updated incidences and mortalities of major cancers in China, 2011. Chin J Cancer. 2015;34(3):53.

2. Jemal A, Bray F, Center MM, Ferlay J, Ward E, Forman D. Global cancer statistics. CA Cancer J Clin. 2011;61(2):69-90.

3. Gupta B, Johnson NW. Systematic review and meta-analysis of association of smokeless tobacco and of betel quid without tobacco with incidence of oral cancer in South Asia and the Pacific. PLoS One. 2014;9(11):e113385.

4. Conway DI, Petticrew M, Marlborough H, Berthiller J, Hashibe M, Macpherson LM. Socioeconomic inequalities and oral cancer risk: a systematic review and meta-analysis of case-control studies. Int J Cancer. 2008;122(12):2811-9.

5. Wong IC, Ng YK, Lui VW. Cancers of the lung, head and neck on the rise: perspectives on the genotoxicity of air pollution. Chin J Cancer. 2014;33(10):476-80.

6. LV W. Description of economic geography features and strategies of regional development integration Guangdong. J Yancheng Inst Technol (Social Science Edition). 2011;24(3):38-43.

7. Chiang CT, Hwang YH, Su CC, Tsai KY, Lian I, Yuan TH, et al. Elucidating the underlying causes of oral cancer through spatial clustering in high-risk 
areas of Taiwan with a distinct gender ratio of incidence. Geospat Health. 2010;4(2):230-42.

8. Saba NF, Goodman M, Ward K, Flowers C, Ramalingam S, Owonikoko T, et al. Gender and ethnic disparities in incidence and survival of squamous cell carcinoma of the oral tongue, base of tongue, and tonsils: a surveillance, epidemiology and end results program-based analysis. Oncology. 2011;81(1):12-20.

9. Warnakulasuriya S. Global epidemiology of oral and oropharyngeal cancer. Oral Oncol. 2009;45(4-5):309-16.

10. Wen Y, Dai X, Wang C, Li L, Fu F, Wang X, et al. A retrospective clinical study of 6539 cases of malignant oral-maxillofacial tumors. Hua Xi Kou Qiang Yi Xue Za Zhi. 2001;19(5):296-9 (in Chinese).

11. Li R, Koch WM, Fakhry C, Gourin CG. Distinct epidemiologic characteristics of oral tongue cancer patients. Otolaryngol Head Neck Surg. 2013;148(5):792-6.

12. Fu JY, Gao J, Zheng JW, Luo JF, Zhang ZY, Xiang YB. Descriptive analysis of oral squamous cell cancer incidence in South and East China. China J Oral Maxillofac Surg. 2014;03:261-5 (in Chinese).

13. Nakao M, Matsuo K, Ito H, Shitara K, Hosono S, Watanabe M, et al. $\mathrm{ABO}$ genotype and the risk of gastric cancer, atrophic gastritis, and Helicobacter pylori infection. Cancer Epidemiol Biomarkers Prev. 2011;20(8):1665-72

14. Wang Z, Liu L, Ji J, Zhang J, Yan M, Zhang J, et al. ABO blood group system and gastric cancer: a case-control study and meta-analysis. Int J Mol Sci. 2012;13(10):13308-21.

15. Edgren G, Hjalgrim H, Rostgaard K, Norda R, Wikman A, Melbye M, et al. Risk of gastric cancer and peptic ulcers in relation to $A B O$ blood type: a cohort study. Am J Epidemiol. 2010;172(11):1280-5.

16. Zhang BL, He N, Huang YB, Song FJ, Chen KX. ABO blood groups and risk of cancer: a systematic review and meta-analysis. Asian Pac J Cancer Prev. 2014;15(11):4643-50.

17. Greer JB, Yazer MH, Raval JS, Barmada MM, Brand RE, Whitcomb DC. Significant association between $\mathrm{ABO}$ blood group and pancreatic cancer. World J Gastroenterol. 2010;16(44):5588-91.

18. Ben $Q$, Wang $K$, Yuan $Y$, Li Z. Pancreatic cancer incidence and outcome in relation to $\mathrm{ABO}$ blood groups among Han Chinese patients: a casecontrol study. Int J Cancer. 2011;128(5):1179-86.

19. Wolpin BM, Kraft P, Gross M, Helzlsouer K, Bueno-de-Mesquita HB, Steplowski E, et al. Pancreatic cancer risk and ABO blood group alleles: results from the pancreatic cancer cohort consortium. Cancer Res. 2010;70(3):1015-23.

20. Poole EM, Gates MA, High BA, Chanock SJ, Cramer DW, Cunningham $J \mathrm{M}$, et al. ABO blood group and risk of epithelial ovarian cancer within the Ovarian Cancer Association Consortium. Cancer Causes Control. 2012;23(11):1805-10.

21. Singh $K$, Kote S, Patthi B, Singla A, Singh S, Kundu H, et al. Relative risk of various head and neck cancers among different blood groups: an analytical study. J Clin Diagn Res. 2014;8(4):C25-8.

22. Wang W, Liu L, Wang Z, Lu X, Wei M, Lin T, et al. ABO blood group and esophageal carcinoma risk: from a case-control study in Chinese population to meta-analysis. Cancer Causes Control. 2014;25(10):1369-77.

23. Gong Y, Yang YS, Zhang XM, Su M, Wang J, Han JD, et al. ABO blood type, diabetes and risk of gastrointestinal cancer in northern China. World J Gastroenterol. 2012;18(6):563-9.

24. Urun Y, Utkan G, Cangir AK, Oksuzoglu OB, Ozdemir N, Oztuna DG, et al. Association of $\mathrm{ABO}$ blood group and risk of lung cancer in a multicenter study in Turkey. Asian Pac J Cancer Prev. 2013;14(5):2801-3.
25. Xu WH, Zheng W, Xiang YB, Shu XO. ABO blood type is associated with endometrial cancer risk in Chinese women. Chin J Cancer. 2011;30(11):766-71.

26. Klein AP, Lindstrom S, Mendelsohn JB, Steplowski E, Arslan AA, Buenode-Mesquita $H B$, et al. An absolute risk model to identify individuals at elevated risk for pancreatic cancer in the general population. PLoS One. 2013;8(9):e72311.

27. Joh HK, Cho E, Choueiri TK. ABO blood group and risk of renal cell cancer. Cancer Epidemiol. 2012;36(6):528-32.

28. Gates MA, Wolpin BM, Cramer DW, Hankinson SE, Tworoger SS. ABO blood group and incidence of epithelial ovarian cancer. Int J Cancer 2011;128(2):482-6.

29. Urun Y, Ozdemir NY, Utkan G, Akbulut H, Savas B, Oksuzoglu B, et al. ABO and Rh blood groups and risk of colorectal adenocarcinoma. Asian Pac J Cancer Prev. 2012;13(12):6097-100.

30. Chen ZY, Zhao TM, Zhang GL. The distribution of ABO blood group in Chinese. Hereditas. 1982;2:4-7.

31. Schussel JL, Kalinke LP, Sassi LM, de Oliveira BV, Pedruzzi PA, Olandoski M, et al. Expression and epigenetic regulation of DACT1 and DACT2 in oral squamous cell carcinoma. Cancer Biomark. 2015;15(1):11-7.

32. Alnuaimi AD, Wiesenfeld D, O'Brien-Simpson NM, Reynolds EC, McCullough MJ. Oral Candida colonization in oral cancer patients and its relationship with traditional risk factors of oral cancer: a matched casecontrol study. Oral Oncol. 2015;51(2):139-45.

33. Lee CH, Chang JS, Syu SH, Wong TS, Chan JY, Tang YC, et al. IL-1 beta promotes malignant transformation and tumor aggressiveness in oral cancer. J Cell Physiol. 2015;230(4):875-84.

34. Yu KT, Ge C, Xu XF, Zou JC, Zou X, Zhen S. CYP1A1 polymorphism interactions with smoking status in oral cancer risk: evidence from epidemiological studies. Tumour Biol. 2014;35(11):11183-91.

35. Krishna RS, Mejia G, Roberts-Thomson K, Logan R. Epidemiology of oral cancer in Asia in the past decade-an update (2000-2012). Asian Pac J Cancer Prev. 2013:14(10):5567-77.

36. Tang WR, Chen ZJ, Lin K, Su M, Au WW. Development of esophageal cancer in Chaoshan region, China: association with environmental, genetic and cultural factors. Int J Hyg Environ Health. 2015;218(1):12-8.

37. Islami F, Pourshams A, Nasrollahzadeh D, Kamangar F, Fahimi S, Shakeri $R$, et al. Tea drinking habits and oesophageal cancer in a high risk area in northern Iran: population based case-control study. BMJ. 2009;338:b929.

38. Karagulle M, Fidan E, Kavgaci H, Ozdemir F. The effects of environmental and dietary factors on the development of gastric cancer. J BUON. 2014;19(4):1076-82.

39. Li K, Yu P. Food groups and risk of esophageal cancer in Chaoshan region of China: a high-risk area of esophageal cancer. Cancer Invest. 2003;21(2):237-40.

40. Bryere J, Dejardin O, Bouvier V, Colonna M, Guizard AV, Troussard X, et al. Socioeconomic environment and cancer incidence: a French populationbased study in Normandy. BMC Cancer. 2014;14:87.

41. Barrios R, Tsakos G, Garcia-Medina B, Martinez-Lara I, Bravo M. Oral healthrelated quality of life and malnutrition in patients treated for oral cancer. Support Care Cancer. 2014;22(11):2927-33.

42. Ahrens W, Pohlabeln H, Foraita R, Nelis M, Lagiou P, Lagiou A, et al. Oral health, dental care and mouthwash associated with upper aerodigestivetract cancer risk in Europe: the ARCAGE study. Oral Oncol. 2014;50(6):616-25. 